\title{
As mudanças na empresa: por que elas são raras e tardias?
}

\section{Resumo}

Este artigo desenvolve uma reflexão sobre as dificuldades de mudanças nas empresas, traçando um paralelo entre imaginação criativa, inovação e mudança organizacional, detendo-se, em particular, na importância da cultura organizacional como um fator inibidor ou estimulador das mudanças. $\mathrm{O}$ artigo conclui apresentando vários pré-requisitos básicos, para se conseguir mudar com sucesso.

\section{Abstract}

This article develops a reflection on the difficulties of changes in the companies by tracing a parallel between creative imagination, innovation and organizational change, lingering in particular, in the importance of the organizational culture as an inhibiting or stimulating factor of the changes. The article concludes by presenting some basic prerequisites to obtain it to move successfully.

\section{Introdução}

Grande parte dos processos de mudanças ${ }^{1}$ radicais nas empresas acaba fracassando. Não por mera coincidência, essas tentativas mal- sucedidas nos remetem às reformas constitucionais: todos concordam com elas, desde que sejam feitas à custa dos outros.

Não há nada mais fascinante e, ao mesmo tempo, frustrante como a observação da vida brasileira, diariamente cheia de surpresas e paradoxos, principalmente ao observar o grau e a velocidade das mudanças entre nós, uma sociedade eclética e heterogênea.
Quando se trata de empresas ou de instituições, as mudanças não ocorrem com a amplitude e a velocidade necessárias para alcançar o resto do mundo. Entre nós, as coisas acabam mudando, mas sempre com atraso, às vezes, com um século de atraso, como ocorreu com a abolição da escravatura. $\mathrm{Na}$ verdade, a própria Constituição Brasileira, refletindo as necessidades de nossos representantes no Congresso, foi feita para impedir as mudanças, privilegiando determinadas minorias desde o tempo das Capitanias Hereditárias.

Mas, se nossas instituições e estruturas públicas e políticas são contra à mudança, o mesmo ocorre com as nossas instituições e empresas privadas. Entre as 10 maiores economias do mundo, nas quais o Brasil se inclui, o Brasil é a menos competitiva, justamente por custarmos a mudar nossas estruturas e métodos de produção, transportes, comercialização e a carga tributária. Nossas empresas operam com altos níveis de ineficiência, apesar dos esforços de modernização de alguns setores e empresas isoladas. A maioria de nossas empresas não está em condições de competir com suas congêneres estrangeiras, principalmente as asiáticas e as americanas.

A razão principal para este estado de coisas é a resistência às inovações e mudanças nas empresas, inerente a nossa cultura e exacerbada pelo período de "fechamento" econômico antes da era Collor. Talvez não seja agradável ouvir, mas o normal, para nós, não é o liberalismo econômico, como também não é a democracia. Sabemos que condições de isolamento são as menos propícias ao surgimento de inovações e à implementação de mudanças. E estas premissas se aplicam não só a nossa vida pública, mas também as nossas empresas privadas,

*Doutorando em Comunicação e Semiótica-PUC, SP. Mestre em Administração: Administração e Planejamento. Especialista em Marketing. Bacharel em Administração. Coordenador do Curso de Administração em Comércio Exterior das Faculdades Integradas "Campos Salles".

"Processo de transformar a maneira de agir de um indivíduo ou de uma organização. 
em geral paternalistas, conservadoras e voltadas para o próprio umbigo.

A partir deste contexto, o objetivo deste artigo consiste justamente em: (1) determinar as causas que bloqueiam as inovações e mudanças nas empresas; (2) sugerir as formas mais viáveis de estimulá-las e acelerá-las.

\section{Dificuldade de Mudanças}

Etimologicamente, a palavra mudança Aenderung, Veränderung, Wechsel significa: (a) ato pelo qual um sujeito permanente se modifica ou é modificado em algumas ou alguma das suas características; e (b) a transformação de uma coisa em outra, ou substituição de uma coisa por outra. Estes dois sentidos foram nitidamente distinguidos por Kant na Crítica da razão pura: atribui exclusivamente à palavra Veränderung o sentido (a) e à palavra Wechsel o sentido (b), ainda que o primeiro evoque mais a idéia de alteração e, o segundo, de alternância. É necessário notar que, mesmo no sentido (b), é preciso, se não um tema, pelo menos um quadro, um contexto definido e que permaneça o mesmo, para que possamos falar de transformação ou de substituição. (Lalande, 1999:711)

A verdadeira causa da falta ou insuficiência das mudanças, nas empresas ou nas sociedades, talvez seja o pensamento em grupo que define as defesas coletivas e as ilusões compartilhadas pelos membros do grupo ao qual cabe tomar as decisões mais importantes sobre o futuro da empresa ou da nação. Consciente ou inconscientemente, o grupo não toma conhecimento das informações que contradizem as suas crenças e valores. Portanto, as suas decisões tendem sempre a valorizar e preservar o que já existe. Algo parecido com a decisão da Cúria Romana, ao mandar queimar Galileu, se este insistisse em afirmar que a Terra não era o centro do universo.

Para Paul Strebel (1992), o grau de resistência à mudança depende do que as pessoas têm a perder ou a ganhar com a mudança, bem como da forma pela qual a cultura da organização molda a resposta a ela.

No trabalho de Beer, Eisenstat e Spector (2000:230) sobre mudança organizacional em seis grandes empresas, eles descobriram que o maior obstáculo à revitalização é a idéia de que ela venha a ocorrer através de programas de mudança por toda a empresa, particularmente quando estes são patrocinados por um grupo de um departamento central da empresa, como o de recursos humanos, que eles denominaram "a falácia da mudança programática".

Não é de admirar que a maioria dos processos de mudanças radicais na empresa acabe em fracasso. São diversas as razões para o fracasso no processo de mudança, refletindo como motivo principal - "o pensamento de grupo" - e como são as empresas fechadas à inovação: (1) defendem as reservas de mercado; (2) tendem a repetir-se; (3) perdem a participação no mercado; (4) falta de visão estratégica; (5) pouca agressividade; (6) paternalismo; (7) super dimensionamento de seu staff; (8) estruturas não orientadas para o mercado; (9) a discussão é evitada; e (10) não há disposição para correr riscos. Esses fatores são sintomas de algo ainda mais profundo: a cultura da empresa, da qual voltaremos a falar mais tarde.

Plus ça change, plus c'est la même chose. Em uma tradução livre do francês, essa frase significa "quanto mais as coisas mudam, mais elas permanecem a mesma coisa". Nas palavras de Maquiavel, "não existe nada mais difícil para se pegar nas mãos, mais perigoso para se conduzir ou mais incerto em termos de sucesso do que tomar a liderança em introduzir uma nova ordem às coisas". Essas duas citações indicam dois conceitos básicos e um tanto opostos sobre mudança: "Nenhuma mudança é a última; e a mudança é difícil”. (Montana \& Charnov, 1999:306307).

As causas de resistência à mudança, de acordo com Mello, citado por Oliveira (1998:471), são: não aceitar aquilo que incomoda; tendência a só perceber aquilo que convém; desconfiança; receio de perder as coisas boas atuais; insegurança pessoal (por desconhecimento ou falta de controle); dependência de ação para com outra pessoa; e necessidade de reagir contra. Entretanto, segundo o autor, pode-se estabelecer alguns processos que permitem reduzir a resistência a estas mudanças, tais como: informar os fatos, necessidades, objetivos e prováveis efeitos da mudança; persuadir sobre fatores que levaram à decisão da mudança; e 
solicitar colaboração no diagnóstico, decisão e planejamento de ações decorrentes.

\section{A Imaginação Criativa}

As palavras criatividade e criativo têm o significado, respectivamente, de "qualidade de criativo"; "capacidade criadora; engenho, inventividade"; "criador" e "imaginação criativa." A idéia de imagem Bild; Vorstellung (Lalande, 1999:517-519) pode significar (a) reprodução, quer concreta, quer mental, daquilo que foi percebido pela visão (com ou sem nova combinação dos elementos que compõem esta imagem). "O ensino pela imagem." "O sentido da visão fornece apenas imagens." Voltaire; (b) repetição mental, geralmente enfraquecida, de uma sensação" (ou, mais exatamente, de uma percepção) precedentemente experimentada; (c) representação concreta construída pela atividade do espírito; combinações novas pelas suas formas, senão pelos seus elementos, que resultam da imaginação criadora. Em particular, representação concreta que serve para ilustrar uma idéia abstrata; e (d) em razão da analogia das imagens (b) e das percepções, e da impossibilidade de as distinguir intrinsecamente em certos casos, freqüentemente estendeu-se a palavra imagem a qualquer apresentação ou representação sensível. A extensão da palavra imagem a sensações ou grupos de sensações diferentes da visão é muito moderna.

Segundo Robert e Michèle Bernstein (1999), não adianta tentar apoderar-se do pensamento alheio, em filosofia, ciência, literatura ou história. Se não conseguirmos imaginar, não conseguiremos inventar nada novo. A imaginação é a capacidade de unir a mente e o corpo, o intelecto e a intuição. Devemos tentar desenvolver o nosso próprio ilusório - revelador - olhar mental. Pensar é sentir, e sentir é pensar. Para eles, devemos estar atentos a: (1) observação $\rightarrow$ todo conhecimento começa pela observação-percepção; (2) criar imagens ou pensamento visual - desenhar uma forma, ou traçar o contorno com os dedos para "vê-la", fechar os olhos para imaginar, imaginar formas que mudam de cor, tamanho, perspectiva etc.; (3) abstração - quando dizemos que as idéias e teorias são abstratas, por não serem matéria. A linguagem do corpo também é abstrata e consegue superar as diferenças cultu- rais; (4) padrões - em toda atividade mental, estamos sempre reconhecendo e formando padrões; (5) analogias - a capacidade de estabelecer analogias é um dos mais importantes instrumentos do pensamento; (6) pense com o corpo - o homem intelectualiza tudo aquilo que faz. $\mathrm{O}$ nosso corpo sabe como fazer coisas que só conseguimos entender depois que as fazemos; (7) pensamento dimensional - consiste em passar de duas dimensões para três, ou vice. versa. Significa também a reprodução em escala e a criação de conceitos a respeito, além do espaço e do tempo que conhecemos; (8) modelização - criar modelos para entender e controlar o mundo; (9) brincar - para permitir que se quebrem os padrões normais de ação, pensamento e percepção; (10) transforme - no pensamento criativo, as idéias e a intuição são transformadas por meio de vários instrumentos pensantes e expressas via uma ou mais linguagens; e (11) sintetize - o resultado obrigatório do pensamento transformador é o entendimento sintético - as impressões sensoriais, sentimentos, $\mathrm{CO}$ nhecimentos e lembranças unem-se de várias maneiras.

Para Fayga Ostrower (1987:29), criar não representa um relaxamento ou um esvaziamento pessoal, nem uma substituição imaginativa da realidade; criar representa uma intensificação do viver, um vivenciar no fazer; e, em vez de substituir a realidade, é a realidade; é uma realidade nova que adquire dimensões novas pelo fato de nos articularmos, em nós e perante nós mesmos, em níveis de consciência mais elevados e mais complexos. Somos, nós, a realidade nova. Daí o sentimento do essencial e necessário no criar, o sentimento de um crescimento interior, em que nos ampliamos em nossa abertura para a vida.

Fayga Ostrower (1987:31), acredita que nas múltiplas formas em que o homem age e onde penetra seu pensamento, nas artes, nas ciências, na tecnologia, ou no cotidiano, em todos os comportamentos produtivos e atuantes do homem, verifica-se a origem comum dos processos criativos numa só sensibilidade. São análogos os princípios ordenadores que regem o fazer e o pensar; na avaliação de resultados (em qualquer área), partimos de noções similares de desenvolvimento e de equilíbrio.

O homem elabora seu potencial criador através do trabalho, como experiência vital, encontrando 
sua humanidade ao realizar tarefas essenciais à vida humana. A criação desdobra-se no trabalho, porquanto este traz em si uma necessidade que gera as possíveis soluções criativas. Nem na arte existiria criatividade, se não pudéssemos encarar o fazer artístico como trabalho, como um fazer intencional produtivo e necessário que amplia em nós a capacidade de viver. Retirando à arte o caráter de trabalho, ela é reduzida a algo de supérfluo, enfeite talvez, porém prescindível à existência humana.

Podemos ainda, segundo Cecília Almeida Salles (1998:43), abordar o aspecto comunicativo do processo criativo sob o ponto de vista de suas relações culturais no tempo e no espaço, onde são travados diálogos inter e intrapessoais. Para a autora "uma mente em ação mostra reflexões de toda espécie. É o artista falando com ele mesmo. São diálogos internos: desvaneios desejando se tornar operantes; idéias sendo armazenadas; obras em desenvolvimento; reflexões; desejos dialogando. São pensamentos que, às vezes, são registrados em correspondências, anotaçôes e diários." Estabelecendo-se, assim, diálogos íntimos.

Certa vez, num debate entre empresários e executivos, ouvi um deles referir-se depreciativamente aos indivíduos dotados de imaginação criativa, que ele chamava de "artistas". Para esse empresário, os "artistas" não deviam fazer parte de uma organização, por serem criadores de casos, indisciplinados, egoístas e pouco confiáveis.

Devemos ter simpatia pelos "artistas", procurar defendê-los, tolerá-los e até protegê-los, porque são eles que disparam as chispas que põem em funcionamento o motor da inovação e da mudança na empresa.

A situação acima é mais comum do que se pensa. As empresas não gostam de abrigar em seu seio elementos destoantes do "pensamento em grupo". Eles acabam provocando conflitos e acabam sendo marginalizados. No entanto, permanece a pergunta: se não dermos chance às mentes criativas, sempre insatisfeitas, quem irá propor as inovações e mudanças de que a empresa precisa? Acima de tudo, quem irá, ao menos, perceber que elas são necessárias?

Realmente, as mentes criativas são raras. Alguns teóricos dizem que todos nós podemos ser criativos, mas isso é muito relativo. O verdadeiro criativo é alguém que enxerga o invisível e sonha com o impossível. Como dizia George Bernad Shaw, "você vê as coisas como elas são e pergunta: por quê? Mas eu sonho com coisas que nunca foram e pergunto: por quê não?"

Concordamos com Bernard Shaw e recomendamos aos empresários que procurem cercar-se de gente de todos os tipos e não apenas de pessoas como ele próprio. A origem das inovações que levam às mudanças é a imaginação criativa do homem, aquela centelha de divindade que nos distingue dos animais e nos leva a buscar sempre uma forma melhor, mais bela ou mais eficiente de fazer as coisas.

Considere ainda esta frase mordaz de Orson Wells a respeito dos suíços: "Na Itália, durante 30 anos, sob os Bórgias, eles tiveram guerra, morte e banhos de sangue. Produziram Michelangelo, Leonardo da Vinci e a Renascença. A Suiça teve amor fraternal e quinhentos anos de democracia e paz. O que eles produziram? O relógio cuco." (Orson Wells)

\section{O Processo de Mudanças na Empresa}

Muitas vezes, a razão principal do fracasso de um processo de mudanças não está na mudança em si mesma, mas no contexto em que ela se insere. Mudar por mudar não leva a nada. Nem sempre o que é novo é melhor. Por isso, as empresas de vanguarda já compreenderam que as mudanças devem ser empreendidas no contexto apresentado na figura $n . \stackrel{0}{1}$, que mostra que há três pré-requisitos básicos, para que no processo se instale - a criatividade, ou espírito criativo dos nossos homens-chave; o rumo, ou motivação desse pessoal, isto é, uma simbiose entre objetivos da empresa e objetivos pessoais de cada um; e, finalmente, a definição clara de objetivos sempre para o mercado - para a mudança a ser implementada.

Só quando estes pré-requisitos são atendidos, poderemos iniciar o processo com a introdução de uma inovação (meio) que leva a uma implementação da mudança (fim).

Na prática, isto só será possível quando a empresa se orienta para o mercado, possui visão estratégica e promove a busca da excelência em tudo o que faz.

Neste contexto, que podemos chamar de "o 


\begin{tabular}{|c|c|}
\hline Missão/Visão estratégica & $\begin{array}{c}\text { Capacidade de antecipar } \\
\text { as ameaças e oportunidades }\end{array}$ \\
\hline $\begin{array}{c}\text { Disposição para o } \\
\text { aprendizado/renovação constante }\end{array}$ & $\begin{array}{c}\text { Introdução de inovãães e mudanças, } \\
\text { visando a obtenção/reforço } \\
\text { de vantagens competitivas }\end{array}$ \\
\hline Cultura organizacional & A busca da excelência \\
\hline
\end{tabular}

novo contexto do marketing" representado na figura n. $\stackrel{0}{2}$, a visão estratégica, a orientação para o mercado e a busca da excelência constituem a base sobre a qual se apoiam e nascem as inovações e as mudanças.

A inovação é um processo que gera algo novo — produto, aplicações, processos, práticas ou sistemas. É um método criativo de ver novas aplicações para o conhecimento existente, combinar pequenos fragmentos de conhecimento para criar uma nova habilidade ou "inventar" novas soluções. A inovação não é um processo bem controlado; pelo contrário, ela depende de pequena disponibilidade de recursos, redundância de esforços, tentativa e erro, experimentação, estar livre de pressões e de maneiras especificadas de se fazer as coisas, autonomia e habilidade de saber se divertir. Conseqüentemente, uma orientação de forte controle organizacional é um antídoto da inovação. Controles burocráticos que limitam as ações e tomadas de decisões demoradas desviam a organização do risco e desencorajam a inovação.

Embora tenhamos a tendência de pensar na inovação como o "cérebro" de um inventor, por trás da maioria das invenções estão grupos de pessoas (Pinchot, 1985; Kanter, 1983; Quinn, 1980). Elas estão envolvidas em muitas facetas do processo de inovação, incluindo a obtenção de recursos, a geração de idéias, o desenvolvimento da inovação, sua entrega ao mercado e/ou sua implementa- ção na organização. As inovações freqüentemente emergem da mistura de múltiplas perspectivas, tais como necessidades do cliente e a base de conhecimento do autor, ou a combinação de duas disciplinas diferentes. Conseqüentemente, a inovação é fomentada na organização que promove a integração de múltiplas perspectivas, ao unir várias peças organizacionais mais intimamente, e pela união mais íntima da organização com seus clientes.

Inovar, muitas vezes, requer que se altere o modelo mental das pessoas em toda a organização em fase de inovação. Brown e Duguid (1991), por exemplo, discutiram inúmeras abordagens criativas que foram usadas para instigar a imaginação das pessoas em toda a Xerox, para que pensassem em novos modelos para o negócio, modelos estes que tirassem proveito da capacidade digital de copiagem. As mesmas técnicas são agora empregadas com os clientes, como uma maneira de moldar a nova tecnologia para adaptar novas maneiras de se fazer negócio.

Os fatores organizacionais descobertos que promovem a inovação são os seguintes:

1. Uma abundante rede de contatos que cruzam as barreiras funcionais.

2. Estruturas organizacionais achatadas que colocam equipes de inovação bem próximas dos tomadores de decisão final.

3. Diversificação de práticas. 
4. Disponibilidade de alocação de recursos e esforços combinados.

5. Horizontes de longo prazo.

6. Contatos freqüentes entre membros organizacionais e grupos externos, tais como outros grupos e clientes geradores de conhecimentos.

7. Incentivos que promovam a tomada de ris$\cos$.

8. Trabalho em equipe.

9. Orientação para o futuro.

10. Estilo gerencial que promova liberdade dentro de amplas diretrizes.

11. Visão clara.

\section{Cultura e Mudanças}

Para Engel, Blackwell e Miniard (2000:394), cultura refere-se a um conjunto de valores, idéias, artefatos e outros símbolos significativos que ajudam os indivíduos a se comunicarem, a interpretarem e a avaliarem como membros da sociedade. Cultura não inclui instintos nem um comportamento idiossincrásico ${ }^{2}$ que ocorre como solução de momento para um problema singular. Cultura inclui elementos tanto abstratos quanto materiais. Os elementos abstratos incluem valores, atitudes, idéias, tipos de personalidade e constructos sumários, como a religião. Componentes materiais incluem coisas como livros, computadores, ferramentas, edifícios e produtos específicos como as calças jeans 501 da Levi's. Elementos materiais de cultura são, às vezes, descritos como artefatos culturais ou como manifestação material da cultura.

A cultura supre as pessoas como um senso de identidade e uma compreensão do comportamento aceitável dentro da sociedade, tais como (1) sentido do eu e do espaço; (2) comunicação e idioma; (3) vestuário e aparência; (4) alimentação e hábitos alimentares; (5) tempo e consciência do tempo; (6) relacionamentos (família, organizações, governos etc.); (7) valores e normas; (8) crenças e atitudes; (9) processos mentais e aprendizagem; e (10) hábitos e práticas de trabalho.

Parece que não há dúvidas de que a cultura organizacional é o fator fundamental que determina a abertura das empresas às inovações e às mudanças. A cultura, isto é, o conjunto de crenças e valores que regem o pensamento do grupo, não garante em si a mesma introdução de inovações e a implementação das mudanças. Mas é ela que cria as condições propícias para que elas ocorram. Mais do que isso: a cultura organizacional, quando orientada para o mercado, oferece rumos e objetivos seguros para o trabalho criativo que leva às inovações e abre o caminho para as mudanças.

As empresas, como as sociedades, apegam-se aos seus valores e crenças, atrasando ou desfigurando as mudanças pretendidas, por mais que haja consenso entre os dirigentes em torno de suas necessidades.

Um valor cultural determinado na sociedade pode levar uma ou mais gerações para ser mudado. Nas empresas, naturalmente, as mudanças podem ocorrer mais rapidamente do que nas sociedades, mas não ocorrem do dia para a noite. Exigem um plano bem elaborado para orientar e apressar as mudanças pretendidas. Na prática, quando é preciso mudar valores de uma cultura organizacional - torná-la menos paternalista e mais orientada para o mercado, torna-se necessário mudar a alta administração, colocando no comando alguém que seja um apóstolo dos novos paradigmas. Geralmente, as empresas onde as mudanças são difíceis de ocorrer têm o seguinte perfil: tradicionalista; defensora do status quo; paternalista; estruturas rígidas; movimentos lentos; tende a repetir-se; não gosta de correr riscos; é pouco agressiva; e pode estar perdendo mercado.

Para Oliveira (1998), as mudanças organizacionais podem provocar uma série de efeitos sobre as pessoas e, a partir desta situação, pode-se ter o início de um processo de resistência a estas mudanças.

Muitas das mudanças não chegam a provocar o real efeito sobre as pessoas, conforme elas já esperavam, mas a simples expectativa deste efeito pode ocasionar a resistência.

Alguns destes efeitos são:

1. Econômicos, tais como mudança no salário ou mudança nos benefícios.

${ }^{2}$ Idiossincrasia. O conjunto dos elementos cuja combinação constitui o temperamento e o caráter individuais. Uma particularidade psicológica saliente num indivíduo 
2. Organizacionais, tais como no poder, mudanças no status, na autonomia ou na carga de trabalho.

3. Sociais, tais como mudanças no relacionamento com o chefe, com os subordinados, com os pares ou com fatores do ambiente empresarial.

Entretanto, estes efeitos pessoais sofrem influência de duas variáveis: (a) características pessoais; e (b) grau de poder do indivíduo. A partir desta posição, o indivíduo pode enquadrar-se numa destas três situações perante as mudanças da empresa:

1. Situação de aceitação;

2. Situação de alienação (ignorar ou acomodar); ou

3. Situação de resistência.

Assim, o administrador ou executivo deve estar atento a todo este processo, para evitar uma quantidade maior de situações que fujam de seu controle.

\section{Conclusão}

Ao longo deste artigo, defendemos a tese de que as inovações e mudanças devem ser cuidadosamente administradas para que tenham êxito. Aliás, esta é a razão pela qual muitas empresas de grande porte possuem hoje um diretor de inovação e mudanças estratégicas.

Os fatores a considerar, para que um programa de mudanças se concretize, são os seguintes:

1. Visão estratégica. As mudanças devem fazer parte de um contexto que inclui um sólido plano estratégico.

2. Cultura empresarial. É preciso identificar o "pensamento do grupo" que retarda as mudanças.

3. Orientação para o mercado. As necessidades e expectativas de nossos clientes são a verdadeira fonte de inspiração das inovações e mudanças.

4. Respeito at ser humano. Muitas empresas falham, porque não conseguem estimular o pensamento criativo e a busca da excelência em seus próprios quadros, confiando demais nos subsídios que vêm de fora. (consultoria)

5. Paciência e realismo. A pressa pode pôr tudo a perder. Esqueça os projetos mirabolantes de "reengenharia" e procure soluções em sintonia com a sua empresa e a sua gente.

Embora os detalhes específicos de programas de mudanças variem de um caso para outro, estas situações apresentam vários pré-requisitos básicos. Primeiro, as pessoas de uma empresa devem reconhecer que a mudança é necessária. Sem esse reconhecimento, envolvimento e participação, serão mínimas as chances de sucesso. Segundo, essas pessoas devem estar comprometidas com a mudança. Para avaliar esse compromisso, é necessária a participação e o envolvimento deles no reexame dos problemas e das práticas adotadas. Terceiro, o escopo dos primeiros esforços de mudança deve ser geralmente um pouco limitado. Por exemplo, os projetos de pequena escala e de tentativa e erro podem ser iniciados. Isso pode ajudar a garantir o sucesso antecipado e impedir grandes falhas que podem diminuir o momento da mudança. Quarto, novas idéias e conceitos devem ser trazidos de fora para auxiliar os membros da organização a encontrarem novas abordagens para aperfeiçoar a eficácia. Quinto, deve haver uma confiança bidirecional em todos os assuntos pertinentes à mudança. Os canais de comunicação devem ser numerosos e abertos. Sexto, as pessoas afetadas pela mudança devem ter habilidades necessárias para enfrentar a nova situação. Podem auxiliar a pensar na mudança, como formação de habilidade e incluir o treinamento como parte do processo de mudança. Por último, a organização deve conceder tempo suficiente, para que a mudança ocorra. O tempo necessário é uma função da distância que a organização deve mudar para preencher a lacuna entre a situação atual e a desejada. Para empresas como um sistema fechado e com orientação interna, o tempo pode ser medido em anos. O progresso pode ser determinado por meio de diversos instrumentos disponíveis.

\section{REFERÊNCIAS BIBLIOGRÁFICAS}

BEER, Michael; EISENSTAT, Russell A.; SPECTOR, Bert. Por que programas de mudança não produzem mudanças. In: HOWARD, Robert et al. Aprendizado Organizacional: gestão de pessoas para a inovação contínua. (Trad.) Bazán Tecnologia e Lingüística. Rio de Janeiro: Campus, 2000, p. 229-244. 
BROWN, J. S.; UGUID, P. Organizational learning and communities of practice: toward a unifield view of working, learning, and innovation. Organization Science, 2(1),1991:40-57.

ENGEL, James F; BLACKWELL, Roger D.; MINIARD, Paul W. Comportamento do consumidor. (Trad.) Christina Ávila de Menezes. Rio de Janeiro: LTC, 2000.

KANTER, R.M. The change masters. New York: Simon \& Schuster, 1989.

LALANDE, André. Vocabulário técnico e crítico da Filosofia. (Trads.) Fátima de Sá Correia et al. São Paulo: Martins Fontes, 1999.

MONTANA, Patrick J.; CHARMOV, Bruce H. Administração. (Trad.) Robert Brian Taylor. São Paulo: Saraiva, 1999 , p. 306 -320.

MOREIRA, Júlio César Tavares; OLIVIERI NETO, Rafael. (Coords.) Marketing business to business: é fazer ou morrer. São Paulo: Makron, 1998.

MORIN, Edgar. O Método 4. As idéias: habitat, vida, costumes, organização. (Trad.) Juremir Machado da Silva. Porto Alegre: Sulina, 1998.

OLIVEIRA, Djalma de Pinho Rebouças de. Sistemas, organização e métodos: OB̈M uma abordagem gerencial. São Paulo: Atlas, 1998. OSTROWER, Fayga. Criatividade e processos de criação. São Paulo: Vozes, 1987.

PINCHOT, G., III. Intrapreneuring. New York: Harper Collins, 1985.

QUINN, J.B. Strategies for change: logical incrementalism. Homewood, Ill: Business One Irwin, 1980.

ROOT-BERNSTEIN, Michèle; ROOT-BERNSTEIN, Robert. Sparks of genius: the 13 thinking tolls of the world's most creative people. Houghton, 1999.

SALLES, Cecília Ameida. Gesto inacabado: processo de criação artística. São Paulo: Annablume, Fapesp, 1998.

STREBEL, Paul. Breakpoints: How managers exploit radical business change. In: FINANCIAL TIMES. Dominando administração. São Paulo: Makron, 1999, p. 526-532. 